البصيرة: مجلة الدراسات الإسلامية

AL-BASHIRAH: JOURNAL OF ISLAMIC STUDIES

Vol. 2 No. 2 (2020): 283-300

ISSN: $2807-2170$

Website: https://journal.stiba.ac.id

البصيرة

مجلة الصراهات الإصلامية

AL-BASHIRAH

\title{
قدرة حفظ القرآن الكريم وعلاقتها في سهولة تعلم اللغة العربية لدى طالبات المعهد العالي للدراسات الإسلامية واللغة العربية
}

\author{
رحماياني \\ المعهد العالى للدرسات الإسلامية واللغة العربية بمكسر \\ narah82collection@gmail : البريد الإلكتروني \\ عائشة أرشد \\ الجامعة الإسلامية الحكومية علاء الدين بمكسر \\ ichaembas@yahoo.com : البريد الإلكتروني \\ مَكا \\ الجامعة الإسلامية الحكومية علاء الدين بمكسر \\ ilyas.hamka@gmail.com : البريد الإلكتروني
}

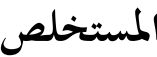

هذه الرسالة حول العلاقة بين القرآن الكريم وسهولة تعلم اللغة العربية لدى طالبات المعهد العالي للدراسات الإسلامية

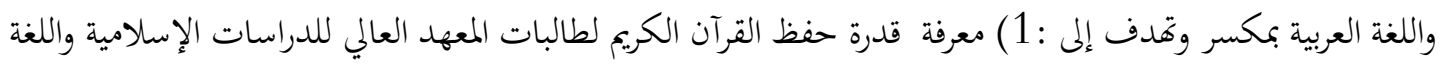

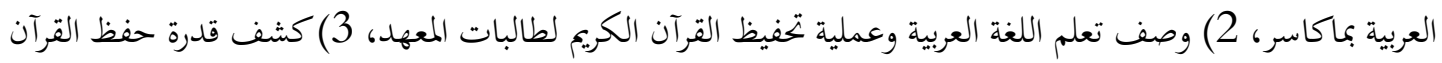

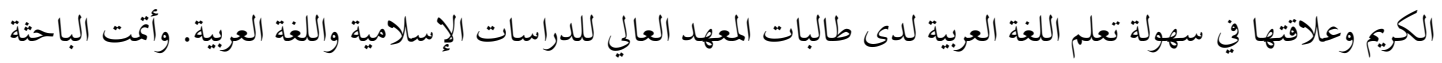

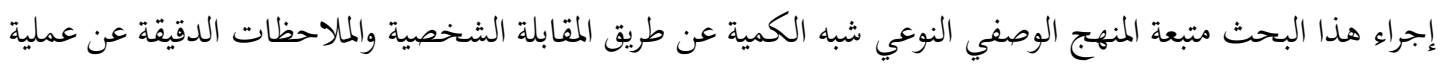

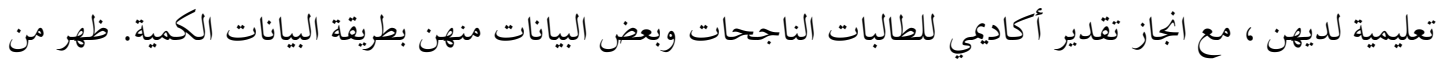

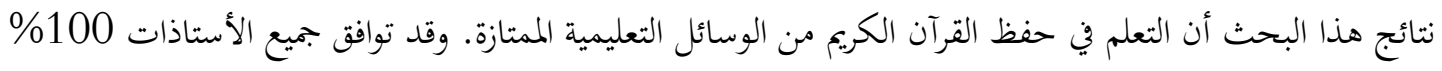

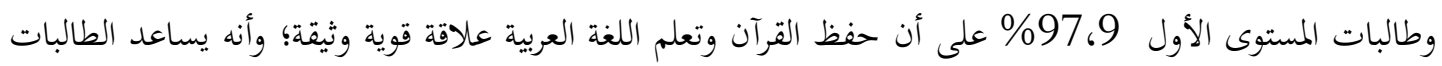
على فهم اللغة العربية، فالطالبة التي حفظت القرآن الكريم قد تعودت على نطق الحروف والكلمات العربية الواردة في الآيات القرآنية. ويتمكن لحافظ القرآن الكريم لغير الناطق بالعبية بناء قدرة تعلم اللغة العربية الصحيحة إجادة سهلة ميسرة ، لأنه يجد فيه تعويد المهارات الأربعة وعناصر اللغة العربية والمواد الدينية والثقافية العامة. الكلمات الدالة: قدرة الحفظ, القرآن, التعلم, اللغة العربية، المعهد العالي للدراسات الإسلامية واللغة العربية. 


\section{البصيرة: مجلة الاراسات الإسلامية \\ AL-BASHIRAH: JOURNAL OF ISLAMIC STUDIES \\ Vol. 2 No. 2 (2020): 283-300 \\ ISSN: $2807-2170$ \\ Website: https://journal.stiba.ac.id

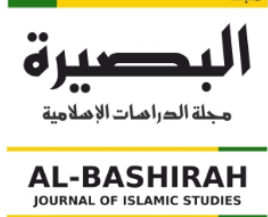

better their Arabic such as the four language skills, the Arabic elements, and the contexts of religious lessons and understandings.

Keywords: memorizing, Al-Qur'an, learning, Arabic, STIBA Makassar

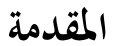

تتضمن التعلم أو التعليم هو نظرية واحدة تتكون من العوامل يرابط بعضها ببعض. ومن عوامله هي

معلم ومتعلم (طالب) وبجتمع ودولة ومنهج دراسي وغرض تعليم وطريقة ومادة دراسية وتقويم ووسائل تعليمية وغيرها. والتعليم عملية تيسير التعلم أي اكتسب المعرفة والمهارات والمبادئ والمعتقدات والعادات. ومن وسائل التعلم والتعليم رواية القصص والنقاش والتدريس والتدريب وغيرها. التعلم والتعليم كثيرا ما يجرى تحت إرشاد معلمين، ومعظم المناهج مختلفة والطرق متنوعة والمواد الدراسية مترابطة، كتعليم اللغة العربية وعلوم القرآن الكريم. فالوسيلة شيء مهم يحتاجون إلى معرفتها لتساعد الطالب في سهولة فهم العلوم وتطبيقها خاصة في تعلم اللغة العربية.

وكل هذا يشير إلى أهمية اللغة العربية في فهم آيات القرآن ومقصدها ومعانيها بشكل واضح. لأن القرآن نزل بلسان عربي فصيح ومبين في عصر كان معظم الناس يتباهون ويتفاخرون ببلاغة وفصاحة لغتهم، وإلمامهم بقواعدها، وضوابطها، وقد نزل القرآن الكريم بمعان، وتركيب، وجمل بليغة جدا، تحتوى بلى على الكثير من التشبيهات والاستعارات, و والأساليب اللغوية البليغة، مما أضاف لمكانة اللغة العربية درجات كثيرة، حتى أصبحت اللغة الخالدة الوحيدة في العالم .11 1 والحقيقة التي لا خلاف عليها، أن قمة تبليغه لغة ما في الشرف وعلو المكانة، أن تكون لغة مبينة ، قادرة على الإشفاف والأفصاح عما في نفس المتحدث ، وبنفس القدر تكون معقولة ومفهومة من قبل السامع أو المتوفي. 2وهذا القرآن هو وثيقة النبوة الخاتمة، ولسان الدين الحنيف، وقاموس اللغة العربية . 32

وإن تعليم اللغة العربية هو عملية تربوية تمدف إلى الدفع والإرشاد والتطوير في بناء قدرة اللغة العربية الصحيحة الفصيحة ، و لما علاقة قوية مرابطة بالقرآن الكريم والحديث الشريف ـ وأن صعوبة اللغة العربية التى يشكو منها الدارسون والمدرسون ليست ناتحة عن طبيعيتها، وإنما هي نابتحة عن ضعف المناهج. وأن

1 1عبد الله علي محمد العبدلي، أهمية اللغة العربية في فهم القرآن الكريم وتفسيره، (دون الطبعة ؛ القاهرة : دار الدلائل)، ص.37.

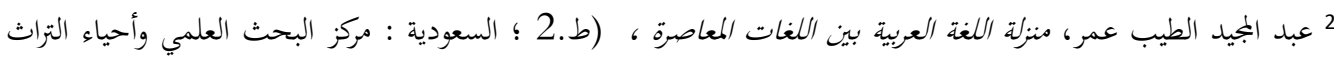

الإسلامي، 2016م / 1437 هـ ) ، ص ـ 19.

3سيد مختار أبو شادي، بداية المريد في فن التجويد ، (ط.5 ؛ القاهرة : دار بن الجو زى، 2011م/ 1432هـ) ص. 20. 


\section{البصيرة: مجلة الاراسات الإسلامية \\ AL-BASHIRAH: JOURNAL OF ISLAMIC STUDIES \\ Vol. 2 No. 2 (2020): 283-300 \\ ISSN: $2807-2170$ \\ Website: https://journal.stiba.ac.id \\ | \\ مجلة الصراهات الإصلامية \\ AL-BASHIRAH}

الدارس غير العربي يستطيع إجادة اللغة, والوصول إلى مستوى الكفاية الذي يتيح له الدخول في الجامعات العربية، بعد سنتين فقط من الدارسة المكثنة . 43 وقد عرفنا أن القرآن الكريم نزل في عربي قريش ، والعرب يعرف اللغة العربية قبل القرآن الكريم والحديث الشريف. وعند بجيء الدين الصحيح وهو الإسلام فيدخلون إليه أفواجا، يختلف في بلدنا إندونيسيا غير الناطق بالعربية ، فيعرف القرآن الكريم أم الدين الإسلامي قبل هذه اللغة الثانية ـ يدرس لهر قراءة القرآن الكريم وتلاوته وحفظه قبل اللغة دون فهم المعنى إلا باللغة الترجمة. فتطور تعليم اللغة العربية لضرورة وجوب حفظها وفهمها وتعليمها تطورا كبيرا، مع كفاءة طالب مختلف. وقد وجدت العربية قبولة واستجابة ،سهولة و صعوبة، يسيرة وعسيرة. فنشهد ونرى آثار هذا القبول وآثار تلك الاستجابة إلى الآن. هذه الآثار تتمثل في كثرة المعاهد والمدارس التي تدرس اللغة العربية، وإقبال الطلاب على هذه المعاهد ، وحرص الآباء والأمهات الكبير على تعليم أبناءهم وبناتم في تلك المعاهد. وبفضل الله وهدايته أصبح مجتمع إندونيسيا يهتموا بعملية تحفيظ القرآن الكريم كما يهتموا بتعليم اللغة العربية. وعرفنا أن أهم المناهج في عملية تعليم اللغة العربية وحفظ القرآن الكريم هو منهج الحفظ. فمن الممكن لحافظ القرآن الكريم لغير الناطق بالعبية بناء قدرة اللغة العبية الصحيحة إجادة سهلة ميسرة ، ويكون وسيلة من وسائل تعليم اللغة العربية، لأنه يجد في تحفيظ القرآن الكريم تعويد المهارات الأربعة وعناصر اللغة العربية والمواد الدينية والثقافية العامة. لذا تريد الباحثة أن تبحث عن هذه الوسيلة التعليمية التي تسهل الطالب في تعلم اللغة العربية. واعتمادا على البيان السابق والملاحظات ترغب الباحثة في كتابة و تقديم بحثها تحت العنوان : قدرة حفظ القرآن وعلاقتها في سهولة تعلم اللغة العربية. وبناء على المسألة الرئيسية فهي تطور إلى بعض المشكلات، وهي ما يلي : 1. كيف قدرة حفظ القرآن الكريم لطالبات المعهد العالي للدراسات الإسلامية واللغة العربية بماكاسر؟ 2. كيف سهولة تعلم اللغة العربية وعملية تحفيظه لطالبات المعهد العالي للدراسات الإسلامية واللغة

$$
\text { العربية بماكاسر؟ }
$$

3. هل قدرة حفظ القرآن الكريم لما علاقة في سهولة تعلم اللغة العربية لدى طالبات المعهد العالي للدراسات الإسلامية واللغة العربية بماكاسر ؟

4عبد الله بن حامد الحامد ، سلسلة تعليم اللغة العربية للناطقين بغيرها (ط.2؛ السعودية : جامعة الإمام محمد بن سعود الإسلامية

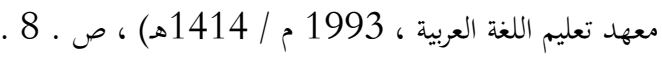


إن المنهج المستخدم في هذا البحث هو المنهج الكيفي الوصفي شبه الكمية، هدفه وصف الظاهرة، وجمع الحقائق والمعلومات التي تقويم في ضوء ماينبعي أن تكون عليه، وفي ضوء معايير أوقيم، واقتراح الخطوات التي يجب أن تكون عليها. 45 يجرى هذا البحث الميداني بمعهد العالي للدراسات الإسلامية واللغة العربية في ماكاسر من بداية شهر نوفمبر 2020 إلى بداية شهر يناير 2021. حيث تقوم بجمع المعلومات من المصدرين العامين، هما : المصدر الأساسي وهو المصدر الذي تحصل منه الباحثة بنفسها المعلومات المتعلقة ببحثها نتيجة عمليتها المباشرة في جمع تلك المعلومات. والمصدر الثاني وهو

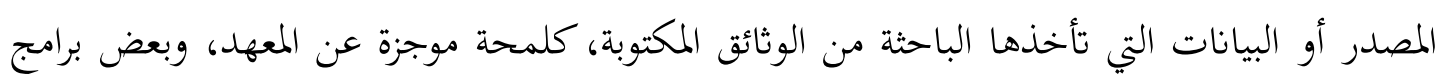
الدراسة الإضافية. أما تحليل البيانات وهو عملية بحث البيانات تجمعها بصورة نظامية تحصل عليها من المقابلات والملاحظات الميدانية، وغيرها من المواد الأخرى، حتى تكون مفهومة بسهولة، ويمكن أن ترسل النتائج إلى الآخرين. 5 وتستخدم الباحثة نموذج مايلزم هابرمان لتحليل البيانات، وهي تخفيض البيانات، وعرض البيانات، والاستنتاجات أو التحقيق.

البحث

المطلب الأول : مفهوم قدرة حفظ القرآن الكريم

معنى كلمة " القدرة " لغة هي الغنى واليسار والقوة76 وفي الاصطلاح : هي الصفة التي يتمكن الحي من الفعل ، وتركه بالإرادة. وصفة تؤثر على قوة الإرادة . 78 والقدرة هي كل ما يستطيع الفرد أداءه في اللحظة الراهنة من أعمال عقلية أو حركية سواء كان ذلك نتيجة تدريب أو بدون تدريب، أو على لئ تذكر قصيدة من الشعر، أو الكلام بليغة أجنية، أو إجراء العمليات الحسابية. 89

5 5 سن شحاتة، البحوث العمية والتربية بين النظرية والثطبيق،( القاهرة: مكتبة الدار العربية للكتاب، 2003م)، ص. Sugiyono, Metodologi Penelitian Kuantitatif, Kualitatif, dan R\&D, h.334. ${ }^{6}$

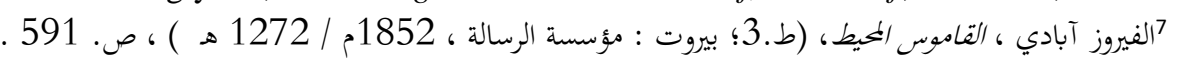

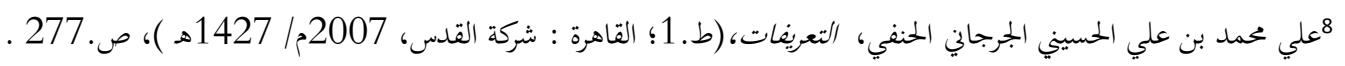

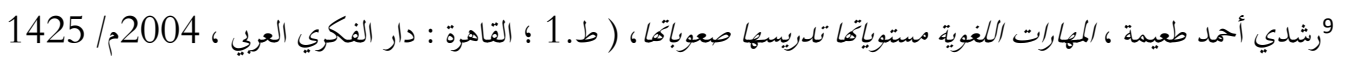


الحفظ لغة هو الضياع والتلف، صانه من الابتذال. 910 الحفظ هو حرسه، والقرآن: استظهره، والمال: رعاه، فهو حفيظ وحافظ, من حفاظ وحفظة. 611 والحفظ هو ضبط الصور المدركة 127، وقيل

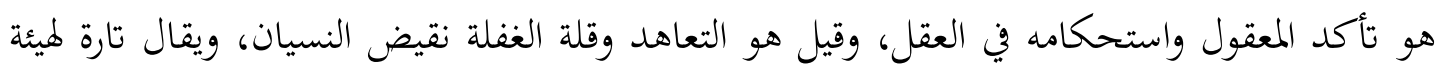

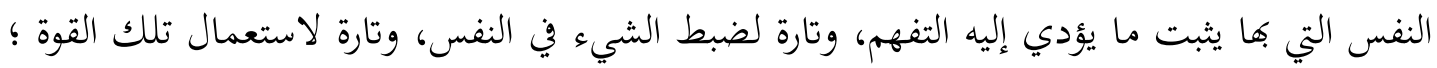

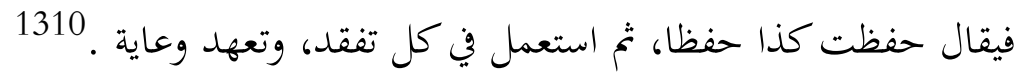

القرآن لغة هو التنزيل العزيز التنزيل. قرأه، و به، كنصره ومنعه، قرءا وقراءة وقرآنا، فهو قارىء من

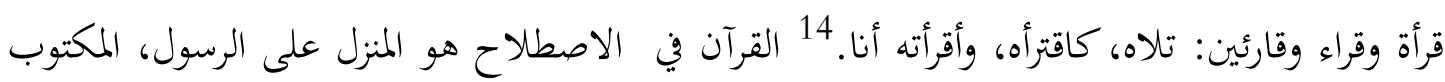

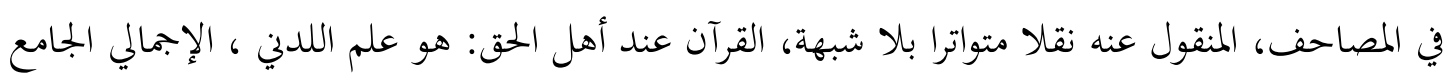
للحقائق كلها.

فبناء على ما سبق من التعريفات المذكورة فتفهم الباحثة خلاصة أن المراد بقدرة حفظ القرآن

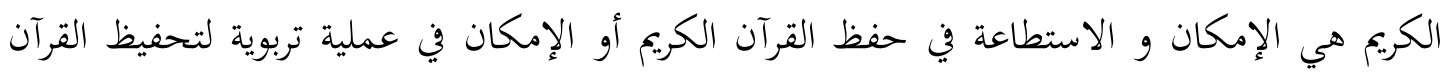

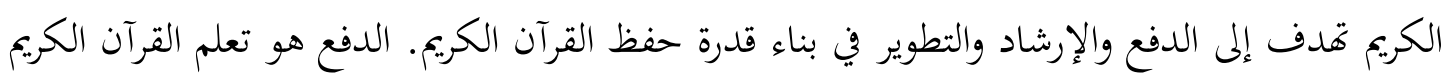

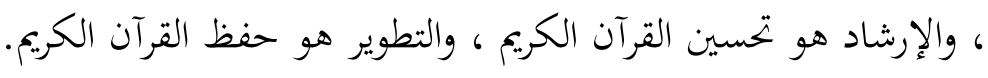

المطلب الثاني : سهولة تعلم اللغة العربية لدى طالبات المعهد العالي للدراسات الإسلامية واللغة العربية بماكاسر.

قسم الإعداد اللغوي هو البرنامج التعليمي من إحدى برامج المعهد الأساسية، قام لتزويد الطالبات

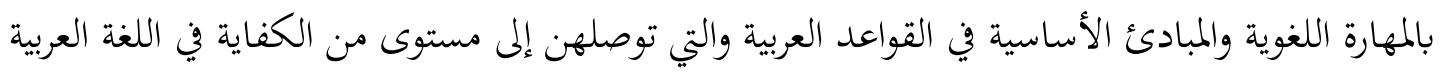

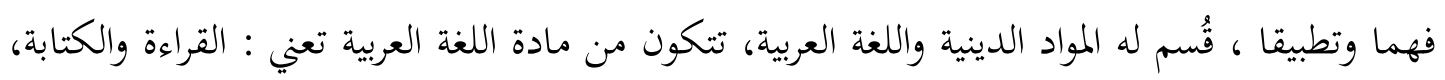

$$
10 \text { لويس مألوف، ، المنجد و الإعلام، (بيروت : دار المشرف، 111 الفيروز آبادي ، القاموس المحيط، ص م } 897 \text {. } 1976 \text { ص. } 142 .
$$$$
13
$$

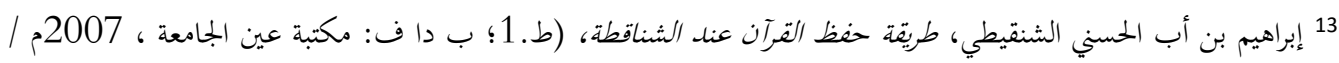
1427هـ ) ، ص. 15

$$
\text { 14 14 الفيروز آبادي ، القاموس المحيط، ص . } 62 .
$$

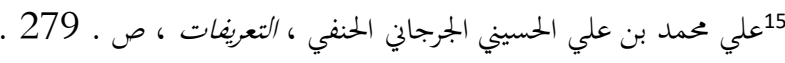


التعبير، تطبيق اللغة، المهارات اللغوية، الحط، والمواد الدينية : كالقرآن الكريم ، علم التجويد ، والتفسير.

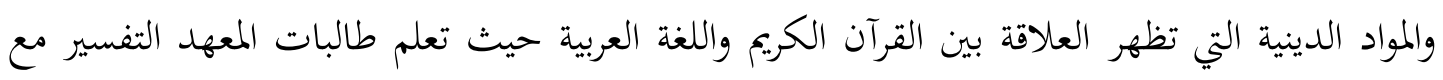

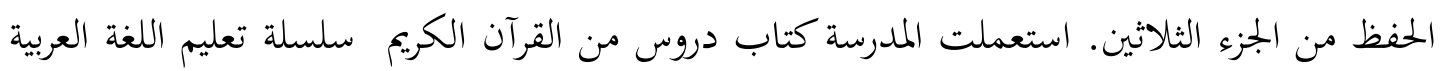

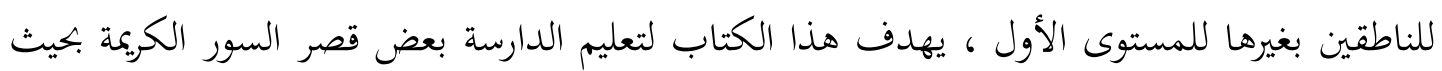

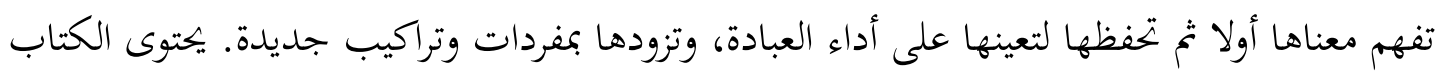
على تفسير سورة الفاتحة، وبعض السور القصيرة من جزء (عم) ؛ من سورة( العصر) إلى سورة ( الناس).

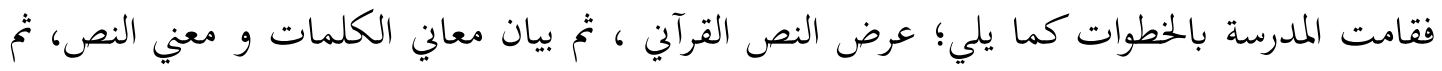

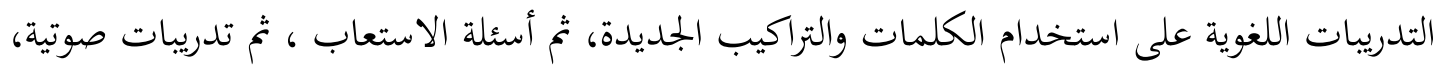
ثم نص للقراءة له علاقة بموضوع الدرس. 16 بعض المعادلات بين حفظ القرآن الكريم واللغة العربية يرشدنا إلى سهولة طالبات المعهد العالي

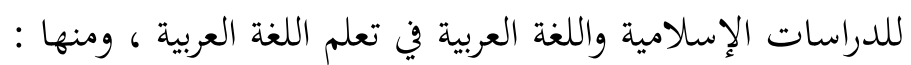
1. أهم الأسس في حفظ القرآن الكريم هي النية الخالصة وكذلك في تعلم اللغة العربية، لأن مفتاح القبول

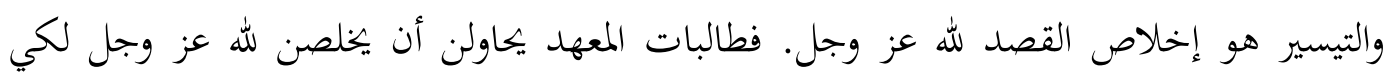
يسهلهن ويعاهن عليه في تعلم القرآن الكريم واللغة العربية.

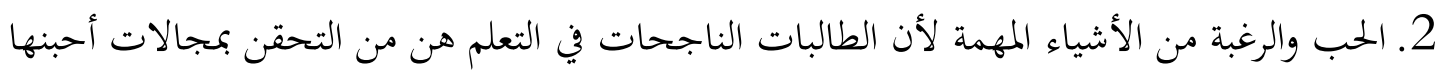

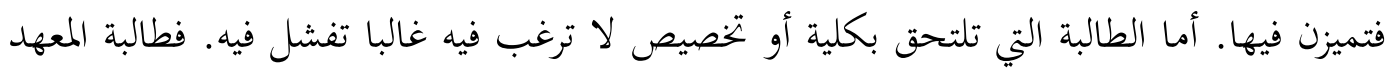

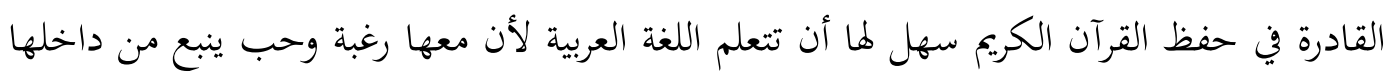

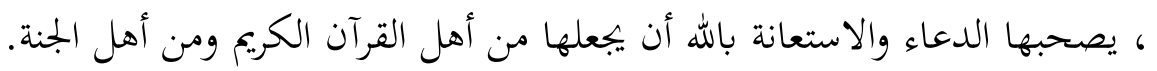

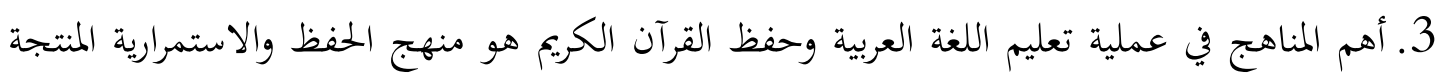

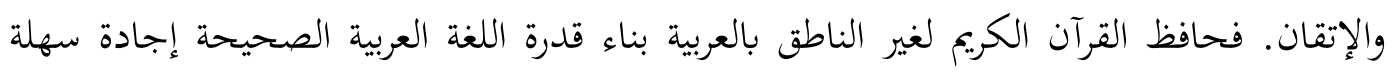

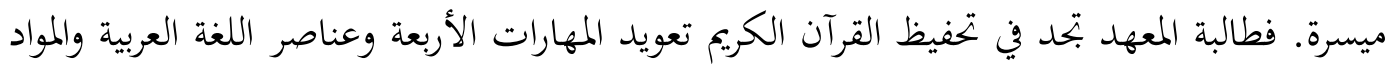
الدينية والثقافية العامة. المطلب الثالث : علاقة حفظ القرآن الكريم وسهولة تعلم اللغة العربية لدى طالبات المعهد العلي لم للدراسات الإسلامية واللغة العربية. 


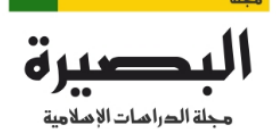

AL-BASHIRAH

إن تعليم اللغة العربية له أربع مهارات هي مهارة الإستماع، ومهارة الكلام، ومهارة القراءة، ومهارة الكتابة، وكذلك في تعليم القرآن الكريم. وعرفنا أن أهم المناهج في عملية تعليم اللغة العربية وحفظ القرآن الكريم هو منهج الحفظ. فالطالبات حافظات القرآن الكريم غير الناطقات بالعربية يستطعن بناء قدرة تعلم اللغة العربية الصحيحة إجادة سهلة ميسرة ، ولهن السهولة والتيسير في تعلمها لأفن يجدن فيه تعويد المهارات الأربعة وعناصر اللغة العربية من مواد العربية و والمواد الدينية والثقافية العامة كعلم التجويد والتفسير وغيرهما.

وبالإضافة ولتأكيد إلى ما لاحظت الباحثة فقامت بعرض البيانات إلى فئات تسهل فهمها قبل الاستنتاجات أو التحقيق ، منها : 1. المقابلة الشخصية مع الأستاذات ، حينما سألتهن الباحثة عن قدرة حفظ القرآن الكريم وعلاقتها في سهولة تعلم اللغة العربية لدى طالبات المعهد العالي للدراسات الإسلامية واللغة العربية , حيث

$$
\text { قالت إحداهن : }
$$

" علاقة حفظ القرآن بتعلم اللغة العربية قوية وثيقة ؛ فالقرآن الكريم أُنْل باللغة العربية الفصيحة. إن حفظ القرآن يساعد الطالب على فهم اللغة العربية، ومعرفة اللغة العربية تسهله في حفظ القرآن. فحفظ القرآن الكريم يثري مفردات الطالب، اسماً كانت أو فعلاً، أو حرفاً، كما أن حفظ القرآن يكسب الطالب كثيرا من التراكيب والعبارات التي تفيده في الكالام والكتابة. ففهم القواعد النحوية والصرفية يسهله في ذكر ضوابط الكلمات بعرفة مواضعها الإعرابية. 17

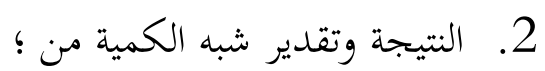
أ. المقابلة الشخصية غير المباشرة مع الطالبات

\begin{tabular}{|c|c|c|c|}
\hline التقدير & النتيجة( \%) & الملاحظات & الرقم \\
\hline جيد & $\% 77$ & 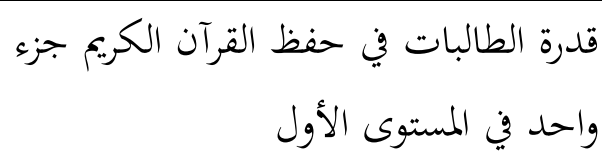 & 1 \\
\hline متمتاز & $\% 97.9$ & تعلم اللغة العربية وحفظ القرآن الكريم & 2 \\
\hline
\end{tabular}


البصيرة: مجلة الاراسات الإسلامية

AL-BASHIRAH: JOURNAL OF ISLAMIC STUDIES

Vol. 2 No. 2 (2020): 283-300

ISSN: $2807-2170$

Website: https://journal.stiba.ac.id

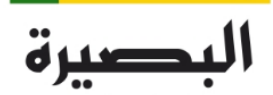

مجلة الصراهات الإهلامية

AL-BASHIRAH

JOURNAL OF ISLAMIC STUDIES

\begin{tabular}{|c|c|c|c|}
\hline متمتاز & $\% 95$ & حفظ القرآن الكريم له أثر في سهولة تعلم & 3 \\
\hline جيد جدا & $\% 73$ & المهارات الأربع في تعلم حفظ القرآن الكريم & 4 \\
\hline جيد جدا & $\% 82$ & 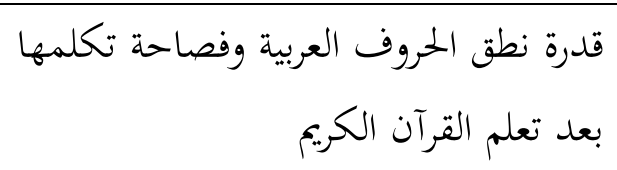 & 5 \\
\hline
\end{tabular}

ب. التقدير الأكاديمي لطالبات المعهد

إن البيانات نأخذها من التقدير الأكاديمي لطالبات المستوى الأول م و ف ف ، مع أن عدد

طالبات المستوى الأول م 33 طالبة ، وعدد طالبات المستوى الأول ف 32 طالبة. والملاحظات مايلي

الجدول الثاني

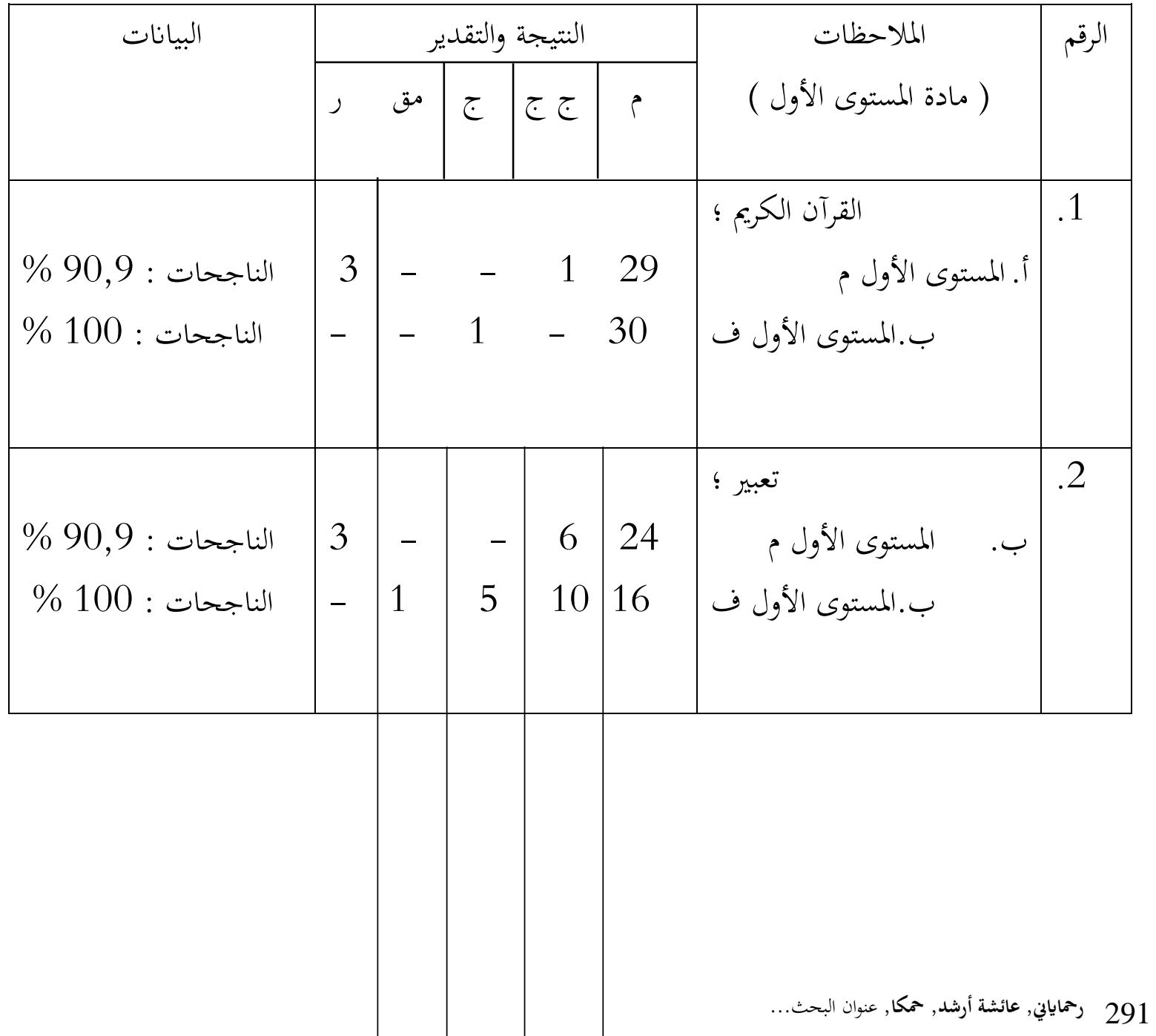


البصيرة: مجلة الدراسات الإسلامية

AL-BASHIRAH: JOURNAL OF ISLAMIC STUDIES

Vol. 2 No. 2 (2020): 283-300

ISSN: $2807-2170$

Website: https://journal.stiba.ac.id

|

مجلة الصراهات الإصلامية

AL-BASHIRAH

JOURNAL OF ISLAMIC STUDIES

\begin{tabular}{|c|c|c|c|c|c|c|c|}
\hline الناجحات : 90,9 \% 100 \% & $\begin{array}{l}3 \\
-\end{array}$ & - & $\begin{array}{l}2 \\
1\end{array}$ & $\begin{array}{l}14 \\
14\end{array}$ & $\begin{array}{l}14 \\
17\end{array}$ & 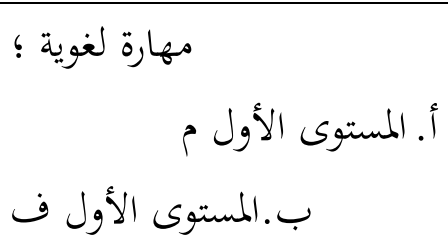 & .3 \\
\hline الناجحات : 90,9 \% 100 \% & $\begin{array}{l}3 \\
-\end{array}$ & $\begin{array}{l}1 \\
-\end{array}$ & $\begin{array}{l}2 \\
1\end{array}$ & $\begin{array}{l}16 \\
4\end{array}$ & $\begin{array}{l}11 \\
27\end{array}$ & 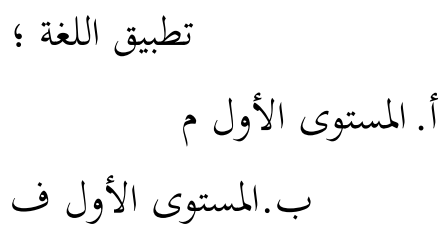 & .4 \\
\hline الناجحات : 87، 87\% & $\begin{array}{l}4 \\
1\end{array}$ & - & 1 & $\begin{array}{l}5 \\
4\end{array}$ & $\begin{array}{l}23 \\
26\end{array}$ & ب. أ. المستوى الأول م المستوى الأول ف & 5 \\
\hline
\end{tabular}




\section{البصيرة: مجلة الدراسات الإسدلامية \\ AL-BASHIRAH: JOURNAL OF ISLAMIC STUDIES \\ Vol. 2 No. 2 (2020): 283-300 \\ ISSN: $2807-2170$ \\ Website: https://journal.stiba.ac.id}

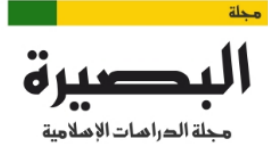

AL-BASHIRAH

JOURNAL OF ISLAMIC STUDIES

3. التقدير الأكاديكي لطالبات الإعداد اللغوي للمستوى الأول م و ف

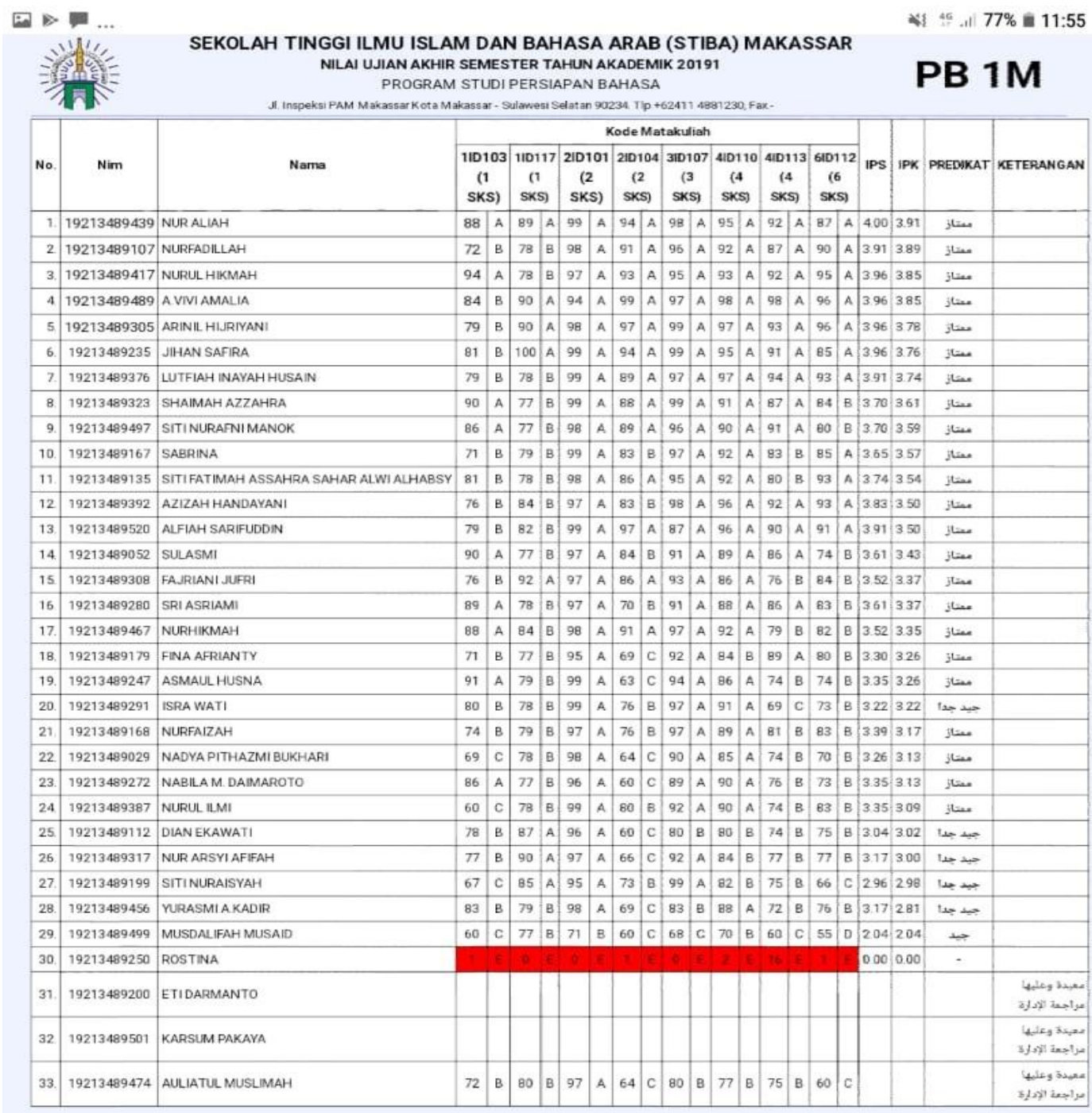

Makassar, 18 Rabiulawal $1442 \mathrm{H} / 04$ November $2020 \mathrm{M}$

Ketua Prodi Perbandingan Mazhab

Saifullah bin Anshor, LC,, M.H

NIY: 1804198508201445

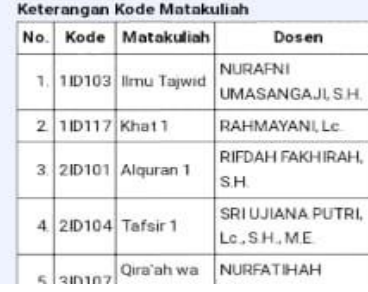

Keterangan Konversi Nilai

No. Mutu Bobot Konversi

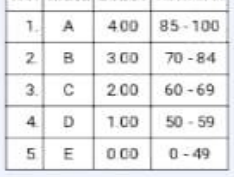

Keterangan

1. Lulus ke Prodi Perbandingan Mazhab.

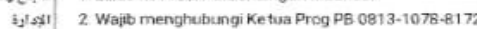
atau Kepala Keputrian 0822-5229-9130 paling lanteat 5 Juni 2020 3. Wajt herregistrasi paling lerribat 26 Juni 2020

1 Mengulang di Program Persiapan Bahasa 1

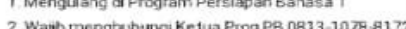
a tau Kepala Keputrian 0822-5229.9130 pating larnbat 5 Juni 2020

3. Waipt herregis vrasi paling lambat 26 Juni 2020 


\section{البصيرة: مجلة الاراسات الإسلامية \\ AL-BASHIRAH: JOURNAL OF ISLAMIC STUDIES \\ Vol. 2 No. 2 (2020): 283-300 \\ ISSN: 2807-2170 \\ Website: https://journal.stiba.ac.id}

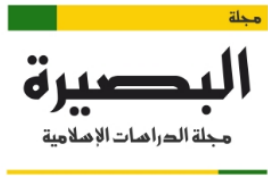

AL-BASHIRAH

JOURNAL OF ISLAMIC STUDIES

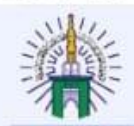

\section{SEKOLAH TINGGI ILMU ISLAM DAN BAHASA ARAB (STIBA) MAKASSAR}

NILAI UJIAN AKHIR SEMESTER TAHUN AKADEMIK 20191

PROGRAM STUDI PERSIAPAN BAHASA

a) $46.1182 \%=11: 04$

\begin{tabular}{|c|c|c|c|c|c|c|c|c|c|c|c|c|c|c|c|c|c|c|c|c|c|c|}
\hline \multirow{3}{*}{$\begin{array}{l}\text { No. } \\
1 .\end{array}$} & \multirow{3}{*}{\begin{tabular}{|c|} 
Nim \\
19213489264 \\
\end{tabular}} & \multirow{3}{*}{\begin{tabular}{|c|} 
Nama \\
FARAH KHAERUN NISA AS \\
\end{tabular}} & \multicolumn{16}{|c|}{ Kode Matakuliah } & \multirow{3}{*}{\begin{tabular}{|l|} 
IPS \\
400 \\
\end{tabular}} & \multirow{3}{*}{\begin{tabular}{|l} 
IPK \\
400
\end{tabular}} & \multirow{3}{*}{$\begin{array}{l}\text { PREDIKAT } \\
j \text { jene }\end{array}$} & \multirow{3}{*}{ KETERANGAN } \\
\hline & & & \multicolumn{2}{|c|}{$\begin{array}{c}110103 \\
(1 \\
\text { SKS) }\end{array}$} & \multicolumn{2}{|c|}{$\begin{array}{c}110117 \\
(1 \\
\text { SKS) }\end{array}$} & \multicolumn{2}{|c|}{$\begin{array}{l}\text { 21D101 } \\
(2 \\
\text { SKS) } \\
\end{array}$} & \multicolumn{2}{|c|}{$\begin{array}{c}\text { 21D104 } \\
(2 \\
\text { SKS }) \\
\end{array}$} & \multicolumn{2}{|c|}{$\begin{array}{c}\text { 31D107 } \\
(3 \\
\text { sKS }) \\
\end{array}$} & \multicolumn{2}{|c|}{\begin{tabular}{|c|}
410110 \\
$(4$ \\
SKS $)$ \\
\end{tabular}} & \multicolumn{2}{|c|}{$\begin{array}{l}\text { 4ID113 } \\
(4 \\
\text { SKS) }\end{array}$} & \multicolumn{2}{|c|}{$\begin{array}{c}\text { 61D112 } \\
16 \\
\text { SKS) }\end{array}$} & & & & \\
\hline & & & 97 & A & 90 & A & 96 & A & 90 & A & 94 & A & $93 \mathrm{~A}$ & A & 93 & A & 99 & A. & & & & \\
\hline 2 & 19213489326 & NURFAIKAH NASRULLA & 91 & A & 80 & B & 100 & A & 97 & A & 98 & $A$ S & $96 \mathrm{~A}$ & A & 93 & A & 97 & A: & $396: 3$ & 398 & معتاز & \\
\hline 3. & 19213489328 & IFFA KARIMAH & 94 & A & 87 & A & 99 & A & 100 & A & 99 & A S & $92 \mathrm{~A}$ & A & 98 & A & 99 & A. & 4003 & 3.96 & متاز & \\
\hline 4 & 19213489423 & FATIMAH AZZAHRA & 94 & A & 79 & B & 99 & A & 100 & A & 99 & A. & 97 A & A & 98 & A & 95 & A: : & 3963 & 393 & معناز & \\
\hline 5. & 19213489330 & NURSANI MALAN & $9 \mathrm{~B}$ & A & 77 & $\mathrm{~B}$ & 100 & A & 88 & $\begin{array}{ll}\text { A } 1 & 1 \\
\end{array}$ & 100 & A: & 89 A & A & 96 & A & 98 & A : & 3963 & 391 & مثلاز & \\
\hline 6. & 19213489495 & AISALALAGA & 96 & A & 81 & B & 100 & A & 94 & $A$ & 98 & A & 98 , & A & 96 & A & 96 & A : & 3963 & 387 & معتاز & \\
\hline 7. & 19213489402 & AISYAH HIDAYAT & 93 & A & 79 & B & 99 & A & 98 & A & 98 & A & 93 A & A & 96 & A & 98 & A : $:$ & 3963 & 3.80 & مشتاز & \\
\hline 8. & 19213489335 & NUR ARIFAH SADAR & 91 & A & 79 & B & 94 & A & 89 & A & 99 & $A$ : & 89 A & A & 97 & A & 95 & A : & 3963 & 3.78 & مشاز & \\
\hline 9. & 19213489316 & HUSNAWATI SUAIB & 91 & A & 73 & $\mathrm{~B}$ & 92 & A & 92 & A 1 & 100 & A. : & 778 & B & 90 & A & 92 & A : & 3783 & 376 & عeمt & \\
\hline 10. & 19213489018 & SITI NURFADHILA NURBAH & 96 & A & 73 & B & 94 & A & 89 & A & 93 & A. & $89 \mathrm{~A}$ & A & 84 & B & 95 & A : & 3783 & 376 & مياز & \\
\hline 11. & 19213489412 & FITRINURCAHYANI & 99 & A & 81 & B & 95 & A & 54 & D & 96 & A 6 & 91 , & A & 85 & A & 90 & A : & 3703 & 363 & معثاز & \\
\hline 12 & 19213489399 & HAYYUL MARYAM & 92 & A. & 80 & B & 99 & A & 51 & D) & 96 & A. & 74 : & B & 92 & A & 87 & A : & 3523 & 357 & معازّ & \\
\hline 13. & 19213489391 & SALMAS & 84 & B & 79 & $B$ & 99 & A & 80 & B & 99 & A: & 86 & A & 87 & A & 98 & A: : & $3833^{3}$ & 357 & معباز & \\
\hline 14 & 19213489293 & FINDIAWATIS MANSUR & 90 & A & 84 & $B$ & 96 & A & 72 & $B$ & 87 & $A:$ & 80 E & B & 84 & $\mathrm{~B}$ & 93 & A: : & 352,3 & 354 & متازي & \\
\hline 15. & 19213489032 & DITA ARIANI & 83 & B & 77 & $B$ & 95 & A & 89 & A & 98 & A : & 80 : & B & 78 & B & 87 & A: : & 3.573 & 3.50 & ميتازي & \\
\hline 16. & 19213489375 & FIVIN ANALISTRA J & 95 & A & 82 & $\mathrm{~B}$ & 95 & A & 60 & c & 74 & 8 & 87 $A$ & A : & 84 & B & 90 & A : & 3.483 & 341 & مثاز & \\
\hline 17. & 19213489365 & REZOY NUR AWALIYA & 95 & A & 81 & B & 96 & A & 75 & B & 97 & A 4 & 96 A & A & 97 & A & 98 & A: & 3.873 & 3.41 & مثاز & \\
\hline 18. & 19213489400 & MUTHIAH AMALIAH SUKARDI & 83 & B & 68 & c & 95 & A & 55 & D & 81 & $\mathrm{~B}:$ & $84 \mathrm{~B}$ & B & 94 & A & 96 & A : & 3,303 & 339 & معتاز & \\
\hline 19 & 19213489349 & KHUSNUL HATIMAH & 96 & A & 73 & B & 95 & A & 65 & c c & 90 & A 6 & $68 \mathrm{C}$ & c & 92 & A & 97 & A : & 3.433 & 339 & ع عباز & \\
\hline 20. & 19213489171 & NUR ANNISA EKA PUTRI & 95 & A & 86 & A & 96 & A & 60 & \begin{tabular}{l|l} 
c 1 & \\
\end{tabular} & 100 & A 5 & $94 \mathrm{~A}$ & A & 87 & A & 88 & A : & 3.833 & 337 & معثاز & \\
\hline 21. & 19213489288 & RISMAYANTI & 90 & A & 78 & B & B9 & A & 75 & $B$ & 90 & A & $73 \mathrm{E}$ & B & 74 & $\mathrm{~B}$ & 92 & A : & 3.523 & 328 & معثاز & \\
\hline 22. & 19213489102 & NURHAFIZAH & 86 & A & 82 & $B$ & 97 & A & 50 & D & 93 & A & $66 \quad c$ & c & 84 & B & 92 & A.: & 3173 & 326 & جيد جدا & \\
\hline 23. & 19213489500 & NUR ARISTA SAPEY & 81 & B & 79 & B & 98 & A & 50 & D & 87 & A: & 83 E & $\mathrm{B}$ & 79 & B & 97 & A : & 3.303 & 3.17 & مشاز & \\
\hline 24 & 19213489164 & SITIFATIMAH ZAHRAH KHUSNUL AINI & 84 & B & 81 & B & 94 & A & 84 & B & 85 & A : & 86 , & A & 73 & B & 90 & A : & 3653 & 315 & مئز & \\
\hline 25. & 19213489222 & DEWI ARFIANI & 91 & A & 73 & B & 95 & A & 60 & c| & 83 & $B$. & $90 \mathrm{~A}$ & A & 81 & B & 94 & A : & 3483 & 3.09 & مثاز & \\
\hline 26. & 19213489282 & SRY DEWI AWALIANI SYAHPUTRI & 89 & A & 70 & B & 100 & A & 60 & c & 93 & A & $61 \mathrm{c}$ & c & 79 & B & 81 & B: & 3.003 & 3.00 & جيد جدأ & \\
\hline 27. & 19213489221 & MASRAWATI & 90 & A & 86 & A & 92 & A & 50 & D) & 95 & A 8 & $82 \mathrm{~F}$ & B & 86 & A & 84 & $8:$ & 3302 & 289 & 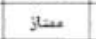 & \\
\hline 28 & 19213489378 & MIFTAHUL HAERAH & 88 & A & 73 & B & 97 & A & 50 & 0 & 82 & B -1 & $72 B$ & B & 71 & B & 81 & B : & 2962 & 287 & بهد جدا & \\
\hline 29 & 19213489170 & FITRATUNNISA & 82 & B & 79 & B & 94 & A & 50 & D & 89 & A : & 600 & c & 75 & 8 & 88 & A. & 3.132 & 283 & جد جدا & \\
\hline 30. & 19213489301 & DIAN MAHARANI & 85 & A & 74 & B & $B 6$ & A & 51 & 0 & 87 & A & $74 \mathrm{~B}$ & B & 71 & 8 & 88 & A : & 3352 & 278 & معتاز & \\
\hline 31. & 19213489312 & DARMAYANTI & 87 & A & 74 & B & 60 & c & 50 & D & 76 & B : & $53 \mathrm{I}$ & D & 73 & B & 32 & B: & 2432 & 243 & جيد & \\
\hline 32 & 19213489292 & DEWI & 69 & c & 77 & B & 93 & A & 55 & D & 60 & c) & $60 \mathrm{C}$ & c & 60 & c & 66 & c & & & & 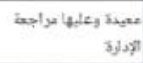 \\
\hline
\end{tabular}

\section{PB 1P}

Makassar, 18 Rabiulawal $1442 \mathrm{H} / 04$ November $2020 \mathrm{M}$

Ketua Prodi Perbandingan Mazhab

Saifullah bin Anshor, LC, M.H.I

NIY 18041985082014459

\begin{tabular}{|c|c|c|c|}
\hline \\
\hline No. & Kode & Matakuliah & Dosen \\
\hline 1. & 11D103 & limu Tajwid & NUPFATIHAH WILDAN, S.H. \\
\hline 2 & 1D117 & Khat 1 & KOKOHI IMAN ILMU AMAL, LC, SH \\
\hline 3. & 21D101 & Alquran 1 & MIRNAWATLSH \\
\hline 4 & 21D104 & Tafsir 1 & SYAMSIAH NUR, LC, SPdI. \\
\hline 5 & 31D 107 & Qira'ah wa Kitabah & HAMSIDAR,SH \\
\hline 6. & $41 D 110$ & To"bir 1 & NURAFNI UMASANGAJI,SH. \\
\hline 7. & 4D113 & Maharat Lughawiyah & AFIAH HAFIZAH KASMAN N, Le. \\
\hline 8 & 6ID112 & Tathbiq Lughah & SRI RESKI WAHYUNI NUR, SH. \\
\hline
\end{tabular}

Keterangan Konversi Nilai

\begin{tabular}{|r|c|c|c|}
\hline No. & Mutu & Bobot & Konversi \\
\hline 1 & A & 400 & $85-100$ \\
\hline 2 & B & 300 & $70-84$ \\
\hline 3 & C & 200 & $60-69$ \\
\hline 4 & D & 100 & $50-59$ \\
\hline 5 & E & 000 & $0-49$ \\
\hline
\end{tabular}

8 6ID112 Tathbiq Lughah SRIRESKI WAHYUNINUR, SH

Copyright 02016 - 2020 Sekolah Tinggi Imu Islam dan Bahasa Arah All Right Reserved

Develop By LontaraGroupNet v7.77 
البصيرة: مجلة الاراسات الإسلامية

AL-BASHIRAH: JOURNAL OF ISLAMIC STUDIES

Vol. 2 No. 2 (2020): 283-300

ISSN: $2807-2170$

Website: https://journal.stiba.ac.id

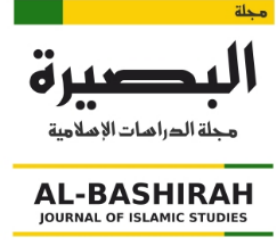

4. الاستبيان من المقابلة الشخصية غير مباشرة لطالبات الإعداد اللغوية للمستوى الأول

Apakah anda mudah menghafal Al- quran?

139 tanggapan
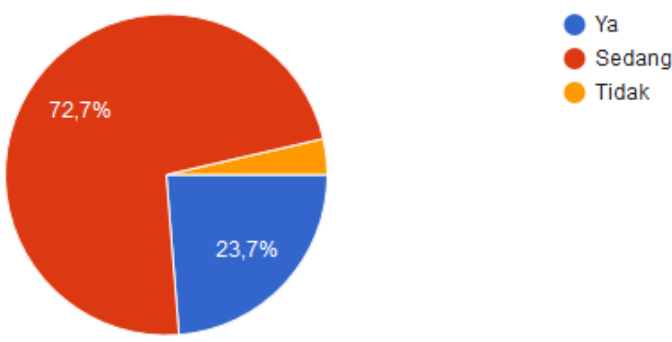

Tidak

Apakah anda mampu menghafal satu juz Al- quran dalam satu semester?

140 tanggapan
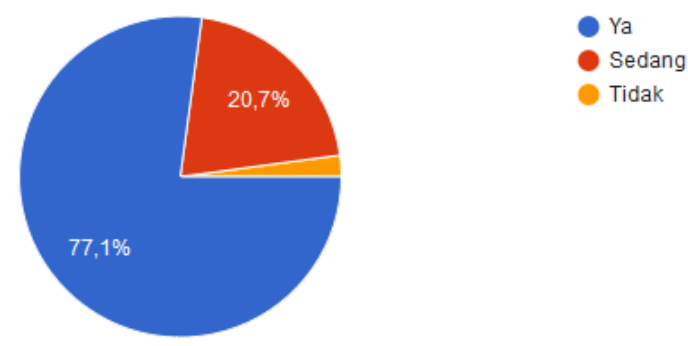

Tidak

Apakah menurut anda belajar bahasa arab ada kesamaannya/ hubungannya dengan pembelajaran Al-quran?

140 tanggapan
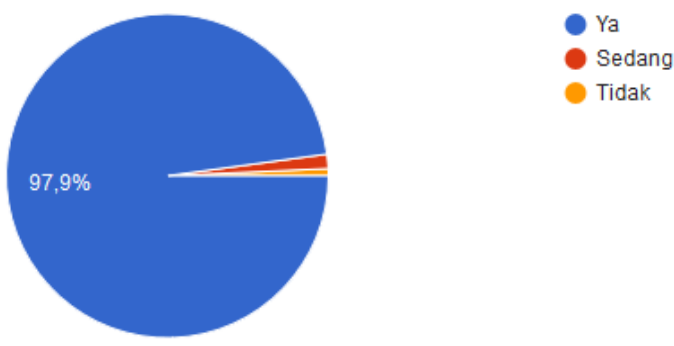
البصيرة: مجلة الاراسات الإسلامية

AL-BASHIRAH: JOURNAL OF ISLAMIC STUDIES

Vol. 2 No. 2 (2020): 283-300

ISSN: $2807-2170$

Website: https://journal.stiba.ac.id

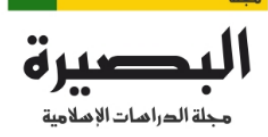

AL-BASHIRAH

Menurut pendapat anda apakah menghafal Al-quran memilik pengaruh terhadap kemudahan dalam belajar bahasa arab?

140 tanggapan

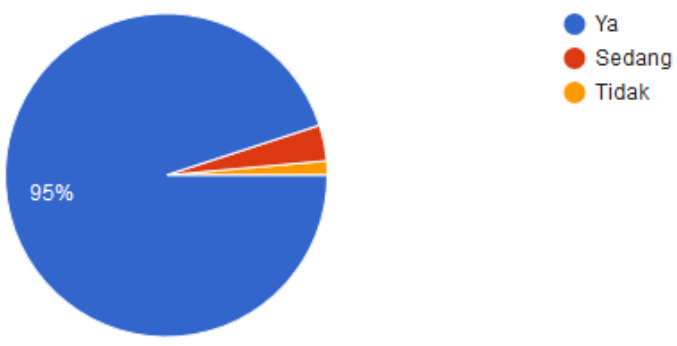

Apakah anda merasa lebih mudah belajar bahasa arab setelah mengikuti kegiatan yang dilaksanakan Raudhatul Huffadzh STIBA (menghafal Alquran)?

140 tanggapan

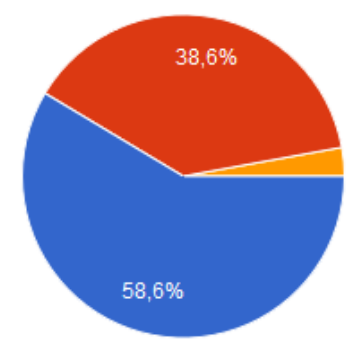

Ya

Sedang

Tidak

Apakah sama metode pengajaran yang diterapkan dalam pembelajaran Alquran dengan bahasa arab?

140 tanggapan

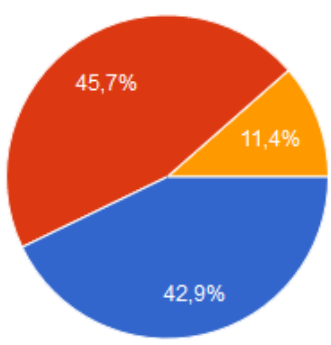


البصيرة: مجلة الاراسات الإسلامية

AL-BASHIRAH: JOURNAL OF ISLAMIC STUDIES

Vol. 2 No. 2 (2020): 283-300

ISSN: $2807-2170$

Website: https://journal.stiba.ac.id

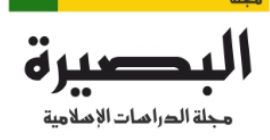

AL-BASHIRAH

Apakah kosa kata yang terdapat dalam Alquran sama dengan yang anda dapatkan dalam maddah bahasa arab?

140 tanggapan

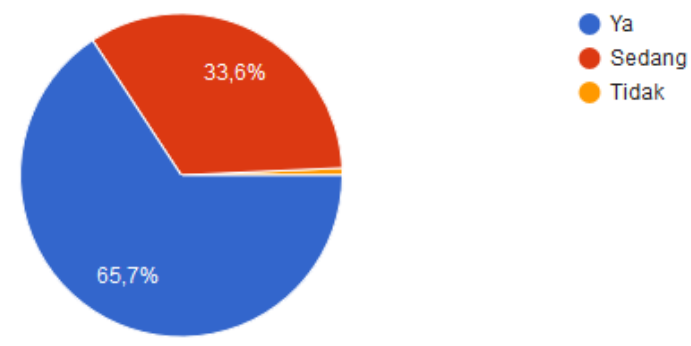

Apakah dalam mempelajari dan menghafal Alquran anda juga mendapatkan empat maharaat

( keterampilan mendengar, berbicara, membaca dan menulis bahasa arab?

140 tanggapan
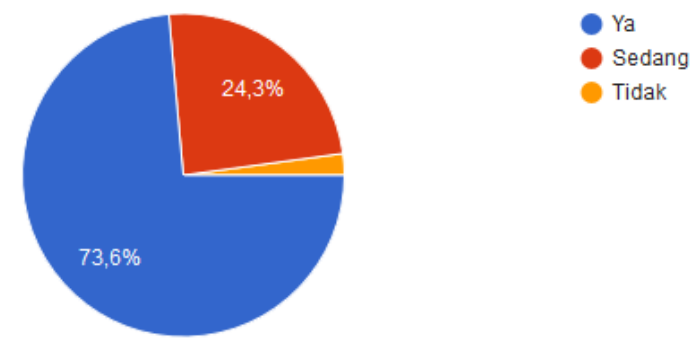

Apakah dengan mempelajari dan menghafal Alquran memudahkan anda dalam menyebut tiap huruf kosa kata bahasa arab dengan fasih?

140 tanggapan

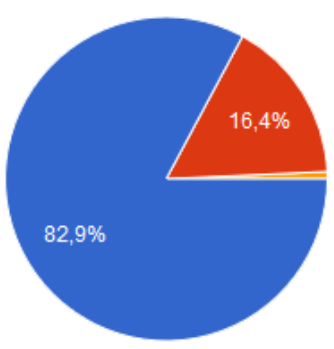


البصيرة: مجلة الاراسات الإسلامية

AL-BASHIRAH: JOURNAL OF ISLAMIC STUDIES

Vol. 2 No. 2 (2020): 283-300

ISSN: $2807-2170$

Website: https://journal.stiba.ac.id

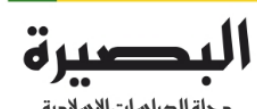

مجلة الصراهات الإصلامية

AL-BASHIRAH

Apakah dengan menghafal Alquran memudahkan anda merangkai kalimat dengan kaidah-

kaidah yang benar dalam bahasa arab?

139 tanggapan

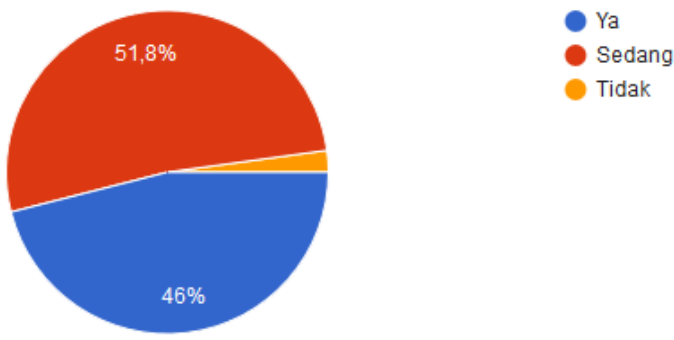

Apakah dengan menghafal Alquran memudahkan anda dalam menggunakan bahasa arab sebagai bahasa sehari-hari?

140 tanggapan

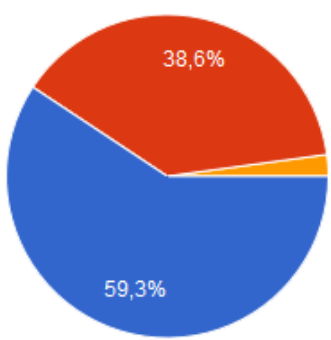

Ya

Sedang

- Tidak

Jumlah hafalan :

102 tanggapan
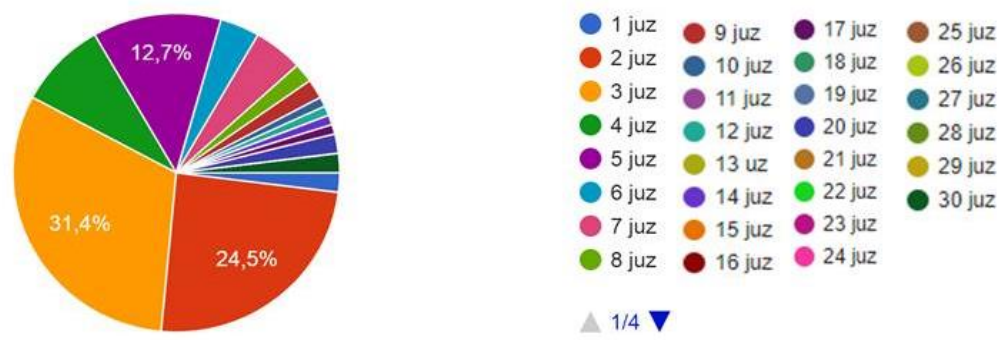

A $1 / 4 \nabla$ 
البصيرة: مجلة الدراسات الإسلامية

AL-BASHIRAH: JOURNAL OF ISLAMIC STUDIES

Vol. 2 No. 2 (2020): 283-300

ISSN: $2807-2170$

Website: https://journal.stiba.ac.id

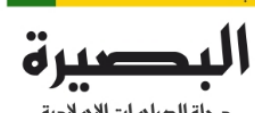

مجلة الصراهات الإصلامية

AL-BASHIRAH

الخاتمة

بناء على ما تقدم عرضه وبيانه خلال هذا البحث المتواضع، استخلصت الباحثة أهم النتائج الآتية : 1. إن حفظ القرآن الكريم في المعهد العالي للدراسات الإسلامية واللغة العربية من أحد المواد الدراسية داخل الفصل، تمدف إلى حفظ الطالبات لكتاب الله تعالى مع مراعات أحكام التجويد، وهي الوسيلة التعليمية الممتازة التي تساعد الطالبات في سهولة تعلم اللغة العربية من المواد الدراسية لهذا المستوى.

2. سهولة تعلم اللغة العربية هي اليسر أو التيسير المنبسط، أي عدم الصعوبة أو المشقة في معرفة اللغة العربية، كما تسهل وتيسر على طالبات المستوى الأول م و ف في المهارة اللغوية والمبادئ الأساسية بالقواعد العربية مع النية الخالصة والحب والرغبة والجها في تعلمها، والتي توصلهن إلى مستوى من الكفاية في اللغة العربية فهما وتطبيقا. فالطالبات حافظات القرآن قد تعودن على نطق الحروف والكلمات العربية الواردة في الآيات القرآنية فلذلك عندما شرعن في دراسة اللغة العربية لن تواجه

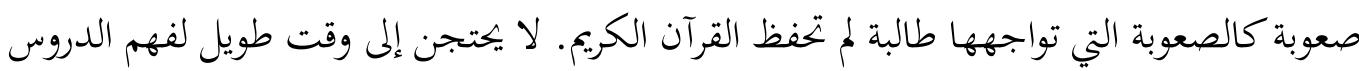
العربية.

إن علاقة حفظ القرآن الكريم بتعلم اللغة العربية قوية وثيقة لا شك فيه. نجدها في سهولة طالبات المعهد العالي للدراسات الإسلامية واللغة العربية عند تعلمها في تعويد المهارات الأربعة وعناصر اللغة العربية و تكلمها الفصيحة مع النية الخالصة لله تعالى، والجها بالحب والرغبة ، ومنهج الحفظ والاستمرارية المنتجة والإتقان . (- م

\section{فهرس المصادر}

Ābādi A-F. Al-Qamūs Al-Muhīd. 3rd ed. Muassasah ar-Risālah; 1852.

Al-'Abdaliy 'Abdullah 'Alī Muhammad. Ahammiyyah Al-Lughah Al-'Arabiyyah F̄̄ Fahmi Al-Qur'an Wa Tafsīrihi. Dār al-Dalāil.

Al-Hāmid 'Abdullāh Ibn Hāmid. Silsilah Ta'lìm Al-Lughah Al-'Arabiyyah Bighairiha. 2nd ed. Jāmi' ah al-Imām Muhammad Ibn Sa'ūd al-Islāmiyyah Ma'had Ta'līm al-Lughah al-'Arabiyyah; 1993.

Al-Hanafiy 'Alī Muhammad Ibn 'Alī al-Husaini al-Jurjānī. At-Ta'rīfāt. Syirkah alQudsiy; 2007. 


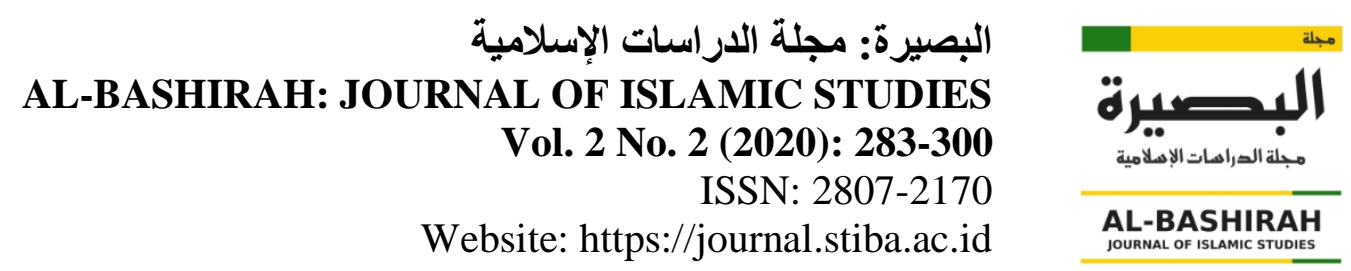

As-Syanqithiy IIA al-H. .. Tharīqah Hifdzh Al-Qur'an 'Inda as-Syanaqithah. 1st ed. Maktabah 'Ain 'al-Jami'ah; 2007.

Ma'lūf L. Al-Munjid Wa Al-I'lām. Dar al-Musyarraf; 1976.

Sugiono. Metodologi Penelitian Kuantitatif, Kualitatif Dan R\&D. ALFABETA; 2009. Syādiy SMA. Bidayah Al-Marīd F̄̄ Fann at-Tajwìd. 5th ed. Dār Ibn al-Jauziy; 2011.

Syahatah H. Al-Buhūts Al-'Amaliyyah Wa at-Tarbiyyah Baina an-Nadzhariyyah Wa at-Tathbīq. 1st ed. Maktabah ad-Dār al-'Arabiyyah Li al-Kitāb; 2003.

Tho'imah RA. Al-Mahārāt Al-Lughawiyyah Mustawayātuha Tadrīsuha Sha'ūbātuha. Dār al-Fikrī al-'Arabiyyah; 2004. 